\title{
Development and Validation of Improved Method for Fingerprint Analysis of Rhizoma Chuanxiong by Capillary Zone Electrophoresis with Ultraviolet-Diode Array Detection
}

\author{
Feng Huan Wei*, Qun Shen and Fei Long Chen \\ Department of Chinese Medicine Pharmaceutics, Southern Medical University, Guangzhou 510515, China
}

*For correspondence: Email: awag7674@smu.edu.cn; Tel: +86 20 61648263; Fax: +86 2061648244.

\begin{abstract}
Purpose: To develop and validate an improved method by capillary zone electrophoresis with photodiode array detection for the fingerprint analysis of Ligusticum chuanxiong Hort. (Rhizoma Chuanxiong).

Methods: The optimum high performance capillary electrophoresis (HPCE) conditions were $30 \mathrm{mM}$ borax containing $5 \% \mathrm{v} / \mathrm{v}$ acetonitrile at $\mathrm{pH}$ 9.6, direct injection of water extract at $0.5 \mathrm{psi}$ for $5 \mathrm{~s}$, $25 \mathrm{kV}$ running voltage at positive power, $20{ }^{\circ} \mathrm{C}$ capillary temperature and $295 \mathrm{~nm}$ detection. Between injections, capillary was rinsed using $0.1 \mathrm{M}$ sodium hydroxide solution for $4 \mathrm{~min}$, with HPCE-grade water for $4 \mathrm{~min}$ and re-equilibrated with running buffer for 2 min at 20 psi, moreover, the running buffer was replaced after three consecutive injections.

Results: Baseline separation of most of the 17 detectable peaks in the water extract could be completed within $21 \mathrm{~min}$. The relative standard deviations (RSD) of precision, reproducibility, and stability were $<2.79 \%$ for retention time and $8.68 \%$ for peak area of the main peaks.

Conclusion: The developed method is simple, fast, reliable and environment-friendly for the fingerprint analysis of Rhizoma Chuanxiong water extract.
\end{abstract}

Keywords: Capillary electrophoresis, Rhizoma chuanxiong, Water extract, Fingerprint analysis, Diode array

Tropical Journal of Pharmaceutical Research is indexed by Science Citation Index (SciSearch), Scopus, International Pharmaceutical Abstract, Chemical Abstracts, Embase, Index Copernicus, EBSCO, African Index Medicus, JournalSeek, Journal Citation Reports/Science Edition, Directory of Open Access Journals (DOAJ), African Journal Online, Bioline International, Open-J-Gate and Pharmacy Abstracts

\section{INTRODUCTION}

In Traditional Chinese Medicine practice, herbal medicines have usually been decocted in water for clinical application since thousands of years, more than $90 \%$ of Chinese herbal medicines contained in Chinese Pharmacopoeia (Volume I of 2010 edition) are taken orally after being decocted with water [1]. This indicates that direct analysis of water extracts of Chinese herbal medicines is a quality control method in accordance with their biological effects. High performance capillary electrophoresis (HPCE) is well-known for analyzing directly water extracts, because the contaminated inner capillary wall can be easily regenerated by rinsing with acid or alkaline solution. The major drawback of HPCE in fingerprint analysis for Chinese herbal medicines is relatively low run-to-run reproducibility of separations caused by the change in the electroosmotic flow (EOF) due to a nonreproducible inner capillary wall [2]. Attempt to improve EOF reproducibility or overcome EOF's effects has been reported, including 
adding markers to sample as aids, different standardization methods and capillary rinsing protocol [3-6].

Rhizoma Chuanxiong (Ligusticum chuanxiong Hort., RC) is a well-known Chinese herbal medicine for treatment of angina, cardiac arrhythmias by improving blood circulation and dispersing blood stasis [7]. The best-known habitat of RC is been acknowledged as Sichuan Province. More than $90 \%$ of RC materials used in clinical are from Sichuan province. In the reported papers about fingerprint analysis of $\mathrm{RC}$, the analyzed samples were mostly prepared with organic solvent, and were analyzed using HPLC with organic reagent as mobile phases, these methods were also time-consuming, usually 40120 minutes for an analysis period [8-10]. The aim of this work is to develop an improved fingerprint analysis method for Rhizoma Chuanxiong and to make a better quality control for it.

\section{EXPERIMENTAL}

\section{Instruments}

The capillary electrophoresis system with photodiode array detector (Beckman P/ACETM MDQ, Beckman Coulter, Inc.CA, USA) was used. Separations were performed in a $75 \mu \mathrm{m}$ inner diameter (ID) fused-silica uncoated capillary with an effective length of $50 \mathrm{~cm}$ and a total length of $60 \mathrm{~cm}$ (Beckman Coulter, Inc. CA, USA). The Data were collected and processed using a 32 KaratTM operating system.

\section{Materials and chemicals}

Ten batches of Rhizoma Chuanxiong samples were collected from different towns in Sichuan province, China (Table 1). All samples were identified by associate professor Zhang Hongwei (Department of Medicinal Plants \& Pharmacognosy, Southern Medical University,
Guangzhou, China) according to pharmacognostic standard documented in I Volume of 2010 Edition of China Pharmacopoeia. All samples were kept in a desiccator.

Tetramethylpyrazine hydrochloride (TMPH) and ferulaic acid (FA) were purchased from National Institute for the Control of Pharmaceutical and Biological Products, Beijing, China (batch numbers were 0817-9803 and 0773-9910, respectively). Ultrapure water prepared with the Millipore Milli-Q SP water purification system (18.2M MMillipore, Bedford, MA, USA) was used for all the buffer solutions and dilution process. All of the reagents, acetonitrile, methanol, ethanol, sodium tetraborate decahydrate (borax, $\mathrm{Na}_{2} \mathrm{~B}_{4} \mathrm{O}_{7} \cdot 10 \mathrm{H}_{2} \mathrm{O}$ ), $\mathrm{NaOH}$ and $\mathrm{HCl}$ were all analytical-reagent grade and purchased from reagent company (Guangzhou, China).

\section{Sample preparation}

The samples were dried in sunshine, weighed (Table 1) and ground into powder. The powder of $\mathrm{RC}$ was exactly weighed $(10.0 \mathrm{~g})$ and put into a $250.0 \mathrm{ml}$ of round-bottom flask, $100 \mathrm{ml}$ water was added next. The mixture was shaken and then was extracted under reflux conditions for $60 \mathrm{~min}$. The entire extraction procedure was repeated twice. The extracted solutions were combined, quantified to $200 \mathrm{ml}$ with water and centrifuged at $2500 \mathrm{rpm}$ at $4^{\circ} \mathrm{C}$ for $15 \mathrm{~min}$, finally the supernatant as sample solutions was transferred into a new tube and stored for analysis at $4^{\circ} \mathrm{C}$. Sample solutions were filtered with a $0.22 \mu \mathrm{m}$ membrane filter (Supelco Inc., Bellefonte, PA, USA) before injection.

\section{Preparation of reference standard solutions}

Tetramethylpyrazine hydrochloride solution (25 $\mu \mathrm{g} / \mathrm{ml}$ ) and $10 \mu \mathrm{g} / \mathrm{ml}$ of ferulaic acid solution were prepared with $0.1 \mathrm{M}$ hydrochloric acid aqueous solution and methanol, respectively.

Table 1: The ten batches of Rhizoma Chuanxiong collected from different towns of Sichuan Province

\begin{tabular}{lll}
\hline Sample no. & Origin & Weight (g, approx.) \\
\hline 01 & Mengyang town, Peng region & 41 \\
02 & Aoping town, Peng region & 35 \\
03 & Aoping town, Peng region & 40 \\
04 & Xindu town, Xindu region & 33 \\
05 & Xindu town, Xindu region & 48 \\
06 & Shiyang town, Dujiangyan & 50 \\
07 & Shiyang town, Dujiangyan & 37 \\
08 & Zhuwa town, Dujiangyan & 45 \\
09 & Daguan town, Dujiangyan & 49 \\
10 & Daguan town, Dujiangyan & 39 \\
\hline
\end{tabular}




\section{Optimization of CZE conditions}

\section{Effect of sodium tetraborate solution}

The electro-osmotic flow can be modified by adjusting the concentration and ionic strength of buffer solution. The running voltage and capillary temperature were set at $25 \mathrm{kV}$ and $20{ }^{\circ} \mathrm{C}$, respectively. $20,30,40,50 \mathrm{mM}$ of sodium tetraborate solution were studied by the separation and appropriate migration time of composition peaks.

\section{Effect of organic solvent modifier}

Organic solvent can improve the separation performances and the selectivity of CZE by influencing the effective mobility of the analytes and the mobility of EOF [11]. Acetonitrile (10 $\% \mathrm{v} / \mathrm{v})$ and methanol (10 \% v/v) were added to 30 $\mathrm{mM}$ sodium tetraborate solution as additive, respectively. One of the organic solvents was chosen as a modifier.

\section{Effect of buffer $\mathrm{pH}$ value}

Buffer $\mathrm{pH}$ can affect the EOF rate and the degree of ionization of analytes. To obtain the baseline resolution of the complex ingredients in Rhizoma Chuanxiong $(\mathrm{RC})$ ) water extract, its $\mathrm{pH}$ at 9.0, 9.3 and 9.6 in $30 \mathrm{mM}$ sodium tetraborate solution containing $5 \% \mathrm{v} / \mathrm{v}$ acetonitrile was evaluated. The optimum $\mathrm{pH}$ value was obtained by trickling into an appropriate amount of $0.1 \mathrm{M} \mathrm{NaOH}$ solution.

\section{Effect of capillary rinse procedures}

The reproducibility of migration times and peak areas strongly depends on the capillary rinse procedures between each run in CZE system [12]. Capillary rinsing can make the system return to the initial running conditions, so the influence of the EOF variation is reduced [13-14]. The total rinsing time was set to $10.0 \mathrm{~min}$ in order to compare efficiency of rinsing methods under the same time consumption. To achieve maximal reproducibility of results, the buffer was renewed from the inlet and outlet reservoirs after three consecutive injections.

\section{Validation of method}

Precision and reproducibility were investigated by five successive analysis of the same No. 2 sample and five replicates of the No. 2 sample, respectively. The same solution of No.2 sample was analyzed at different time points $(0,4,8,16$, 24 and $48 \mathrm{~h}$, between the samplings, the sample was kept at $4^{\circ} \mathrm{C}$ ) and evaluated for the stability test.

\section{Fingerprint analysis}

Data analysis was carried out by a professional software named Similarity Evaluation System for Chromatographic Fingerprint of TCM (Version 2004 A), recommended by the Chinese Pharmacopoeia Committee for evaluating similarities of different electropherograms by computing the correlation coefficient and/or cosine value of vectorial angel. In this study, all the results were treated by correlation coefficient [15]. The reference electropherogram of Rhizoma Chuanxiong was established by processing electropherograms of 10 batches of Rhizoma Chuanxiong from different regions in Sichuan Province.

\section{RESULTS}

\section{Optimization of HPCE conditions}

Concentration increase of borax solution improved the separation of phenolic acid ingredients, simultaneously remarkably increased the migration time of ferulic acid. A better separation and appropriate migration time was achieved at $30 \mathrm{mM}$ (Fig 1). Thus, $30 \mathrm{mM}$ sodium tetraborate buffer was chosen as background electrolyte for subsequent experiments.

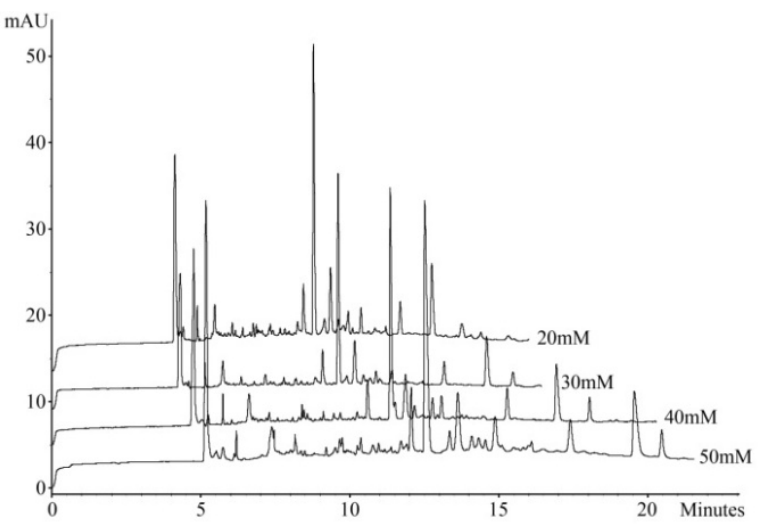

Figure 1: Effect of sodium tetraborate solution concentration on the separation of Rhizoma Chuanxiong water extract. Conditions: Running voltage, $25 \mathrm{kV}$; capillary temperature, $20{ }^{\circ} \mathrm{C}$; wavelength, $295 \mathrm{~nm}$; injection, $0.5 \mathrm{psi}$ for $5 \mathrm{~s}$

The separation performance and peak numbers with $10 \%$ acetonitrile as modifier were better than tetraborate solution alone and than $10 \%$ methanol as modifier. Increasing the concentration of acetonitrile in buffer obviously improved the separation of FA with its neighbouring peaks (Fig 2). However, the 
migration time of FA and its contiguous peaks became long notably. Based on the comprehensive analysis of separation performance, $5 \%$ acetonitrile was chosen for subsequent experiments.

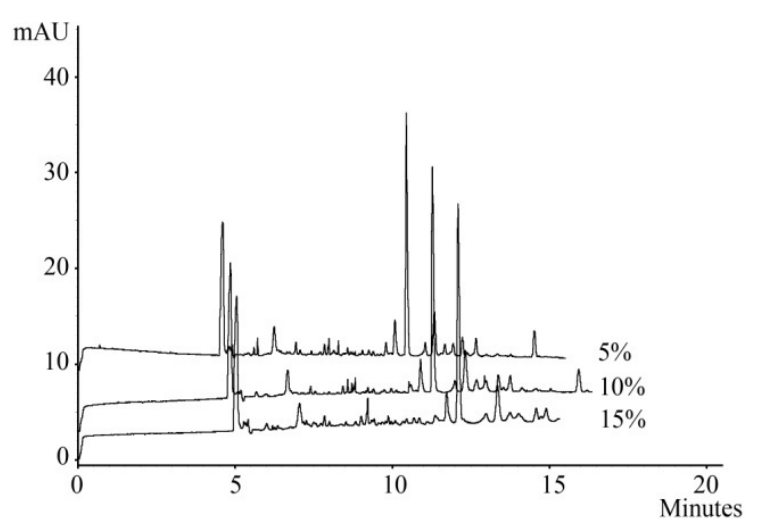

Figure 2: Effect of acetonitrile concentration in buffer on the separation of Rhizoma Chuanxiong water extract. Conditions: sodium tetraborate buffer, $30 \mathrm{mM}$; running voltage, $25 \mathrm{kV}$; capillary temperature $20{ }^{\circ} \mathrm{C}$; wavelength, $295 \mathrm{~nm}$; injection, $0.5 \mathrm{psi}$ for $5 \mathrm{~s}$.

The buffer $\mathrm{pH}$ value had little influence on the migration time of TMPH, however increased clearly the migration time and improved the separation of FA and its neighbouring peaks when the $\mathrm{pH}$ was increased from 9.3 to $9.6, \mathrm{pH}$ less than 9.3 the resolution of FA and its neighbouring peaks was decreased (Fig.3). Considering the higher $\mathrm{pH}$ increasing migration times, the best $\mathrm{pH}$ value of running buffer was 9.6.

Obviously, running voltage, capillary temperature and detection wavelength also have effect on migration time, separation and peak numbers of samples. A satisfactory fingerprint of $\mathrm{CR}$ water extract has been developed based on $25 \mathrm{kV}$ running voltage, $20^{\circ} \mathrm{C}$ capillary temperature and $295 \mathrm{~nm}$ detection wavelength. Therefore, further optimization under these conditions was not continued.

The rinsing procedures and results are shown in Table 2. The RSD values in migration times and in peak areas were less than $3.17 \%$ and $6.25 \%$, respectively, by rinsing with $0.1 \mathrm{M} \mathrm{NaOH}$ for 4.0 min followed by rinsing with water for $4.0 \mathrm{~min}$ and lastly with BGE buffer for 2.0 min.

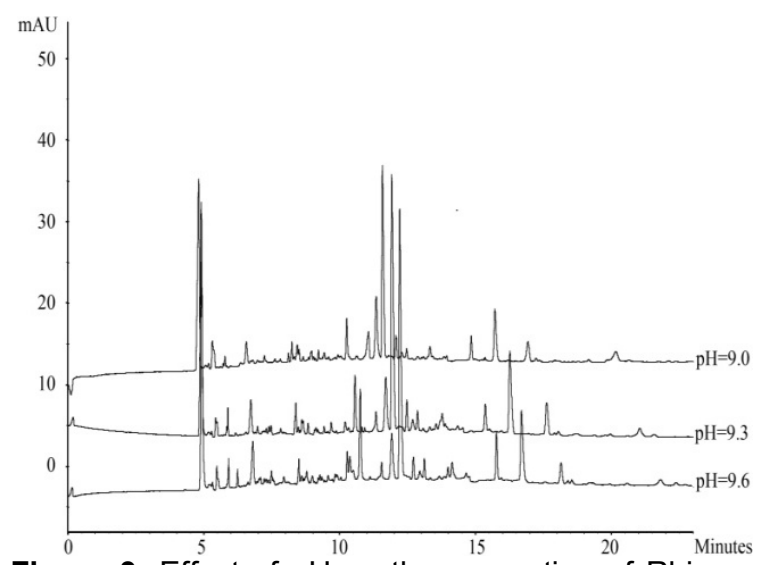

Figure 3: Effect of $\mathrm{pH}$ on the separation of Rhizoma Chuanxiong water extract. Conditions: sodium tetraborate buffer, $30 \mathrm{mM}$ containing $5 \%$ acetonitrile; running voltage, $25 \mathrm{kV}$; capillary temperature, $20{ }^{\circ} \mathrm{C}$; wavelength, $295 \mathrm{~nm}$; injection, $0.5 \mathrm{psi}$ for $5 \mathrm{~s}$.

This improved method for fingerprint analysis of Rhizoma Chuanxiong was as follows: $30 \mathrm{mM}$ borax containing $5 \% \mathrm{v} / \mathrm{v}$ acetonitrile at $\mathrm{pH} 9.6$ as buffer solution, samples were injected at the anodic end at $0.5 \mathrm{psi}$ for $5 \mathrm{~s}, 25 \mathrm{kV}$ at positive power as running voltage, capillary temperature was $20^{\circ} \mathrm{C}$ and $295 \mathrm{~nm}$ as detection wavelength. In addition, between each injection, rinsing the capillary with $0.1 \mathrm{M}$ sodium hydroxide solution for 4 min, with HPCE-grade water for 4 min and reequilibrated with running buffer for 2 min at 20 psi, moreover, the running buffer was replaced

Table 2: Relative standard deviation of migration times and peak areas of characteristic ingredients in Rhizoma Chuanxiong water extracts after different capillary rinsing procedures

\begin{tabular}{|c|c|c|c|c|c|c|c|c|}
\hline \multirow{2}{*}{$\begin{array}{l}\text { Procedure of } \\
\text { preconditioning }\end{array}$} & \multicolumn{8}{|c|}{ Relative standard deviation $(\%, n=5)$} \\
\hline & & Peak 1 & Peak 4 & Peak10 & Peak 11 & Peak 12 & Peak15 & Peak16 \\
\hline Rinsing with distilled water & Migration & 1.09 & 1.47 & 4.59 & 4.78 & 5.06 & 6.39 & 8.25 \\
\hline $\begin{array}{l}\text { ( } 8 \mathrm{~min}) \text {, followed by BGE } \\
(2 \mathrm{~min}) \text { between each run }\end{array}$ & Peak area & 3.76 & 4.60 & 6.72 & 6.38 & 7.33 & 9.67 & 12.21 \\
\hline Rinsing with $0.1 \mathrm{M} \mathrm{HCl}$ (4 & & & & & & & & \\
\hline $\begin{array}{l}\text { min), distilled water ( } 4 \\
\text { min), followed by BGE ( } 2 \\
\text { min) between each run }\end{array}$ & $\begin{array}{l}\text { Migration } \\
\text { Peak area }\end{array}$ & $\begin{array}{l}1.13 \\
4.22\end{array}$ & $\begin{array}{l}1.39 \\
3.52\end{array}$ & $\begin{array}{l}4.48 \\
3.29\end{array}$ & $\begin{array}{l}4.69 \\
7.02\end{array}$ & $\begin{array}{c}5.13 \\
10.36\end{array}$ & $\begin{array}{c}8.23 \\
13.04\end{array}$ & $\begin{array}{l}10.98 \\
10.69\end{array}$ \\
\hline $\begin{array}{l}\text { Rinsing with } 0.1 \mathrm{M} \mathrm{NaOH} \\
\text { ( } 4 \text { min), distilled water ( } 4 \\
\text { min), followed by BGE ( } 2 \\
\text { min) between each run }\end{array}$ & $\begin{array}{l}\text { Migration } \\
\text { Peak area }\end{array}$ & $\begin{array}{l}0.89 \\
2.41\end{array}$ & $\begin{array}{l}1.08 \\
3.06\end{array}$ & $\begin{array}{l}1.73 \\
2.94\end{array}$ & $\begin{array}{l}1.97 \\
4.03\end{array}$ & $\begin{array}{l}2.08 \\
3.04\end{array}$ & $\begin{array}{l}2.11 \\
3.01\end{array}$ & $\begin{array}{l}2.49 \\
3.25\end{array}$ \\
\hline
\end{tabular}


after three consecutive injections. Based on their UV spectra, migration time and standard addition, peak-1 and peak-11 were identified as TMP and FA (two main compounds in RC), respectively. The representative electropherogram of 2-sample was showed in Figure 4.

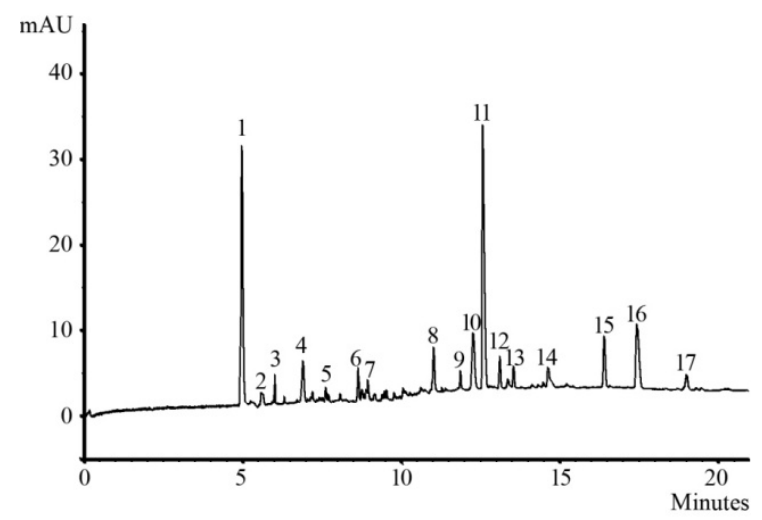

Figure 4: Representative electropherogram of the water extract of Rhizoma Chuanxiong (2-sample). Peak-1 = tetramethylpyrazine; Peak-11 = ferulic acid.

\section{Validation results}

As shown in Table 3, the RSD of migration times and peak areas of characteristic peaks in the precision test, the reproducibility test and the stability test were $<2.79$ and $<8.68 \%$, respectively. The results indicate that the conditions of fingerprint analysis were satisfactory.

\section{Fingerprint analysis}

The electropherograms of 10 batches of RC samples from different regions in Sichun province had good similarity and a reference standard electropherogram was constructed (Fig.5), It indicated there is no obvious difference in the quality, the similarity values are listed in Table 4. These results are identical to the reports about Rhizoma Chuanxiong [8-9].

Table 3: Results of precision, reproducibility and stability with relative standard deviation

\begin{tabular}{|c|c|c|c|c|c|c|}
\hline \multirow{2}{*}{$\begin{array}{l}\text { Peak } \\
\text { no. }\end{array}$} & \multicolumn{3}{|c|}{ RSD of migration time (\%) } & \multicolumn{2}{|c|}{ RSD of peak area (\%) } & \multirow[b]{2}{*}{ Stability } \\
\hline & Precision & Reproducibility & Stability & Precision & Reproducibility & \\
\hline 1 & 0.51 & 0.43 & 1.23 & 2.29 & 2.49 & 3.10 \\
\hline 4 & 0.76 & 0.82 & 1.37 & 2.64 & 3.14 & 3.53 \\
\hline 10 & 1.09 & 2.10 & 2.13 & 3.12 & 4.52 & 3.69 \\
\hline 11 & 1.22 & 2.14 & 2.28 & 4.17 & 5.68 & 6.22 \\
\hline 12 & 1.28 & 2.42 & 2.36 & 3.36 & 6.24 & 5.75 \\
\hline 15 & 1.79 & 2.51 & 2.69 & 3.26 & 8.11 & 7.02 \\
\hline 16 & 2.11 & 2.77 & 2.79 & 4.01 & 7.47 & 8.68 \\
\hline
\end{tabular}

Table 4: The similarity values of 10 samples

\begin{tabular}{|c|c|c|c|c|c|c|c|c|c|c|}
\hline \multirow{2}{*}{$\begin{array}{l}\text { Correlation } \\
\text { coefficient }\end{array}$} & \multicolumn{10}{|c|}{ Sample no. } \\
\hline & 1 & 2 & 3 & 4 & 5 & 6 & 7 & 8 & 9 & 10 \\
\hline $\begin{array}{l}\text { Median } \\
\text { Average }\end{array}$ & $\begin{array}{l}0.997 \\
0.998\end{array}$ & $\begin{array}{l}1.000 \\
1.000\end{array}$ & $\begin{array}{l}0.996 \\
0.997\end{array}$ & $\begin{array}{l}0.998 \\
0.999\end{array}$ & $\begin{array}{l}0.995 \\
0.996\end{array}$ & $\begin{array}{l}0.998 \\
0.998\end{array}$ & $\begin{array}{l}0.997 \\
0.998\end{array}$ & $\begin{array}{l}0.999 \\
0.999\end{array}$ & $\begin{array}{l}0.994 \\
0.996\end{array}$ & $\begin{array}{l}0.991 \\
0.995\end{array}$ \\
\hline
\end{tabular}
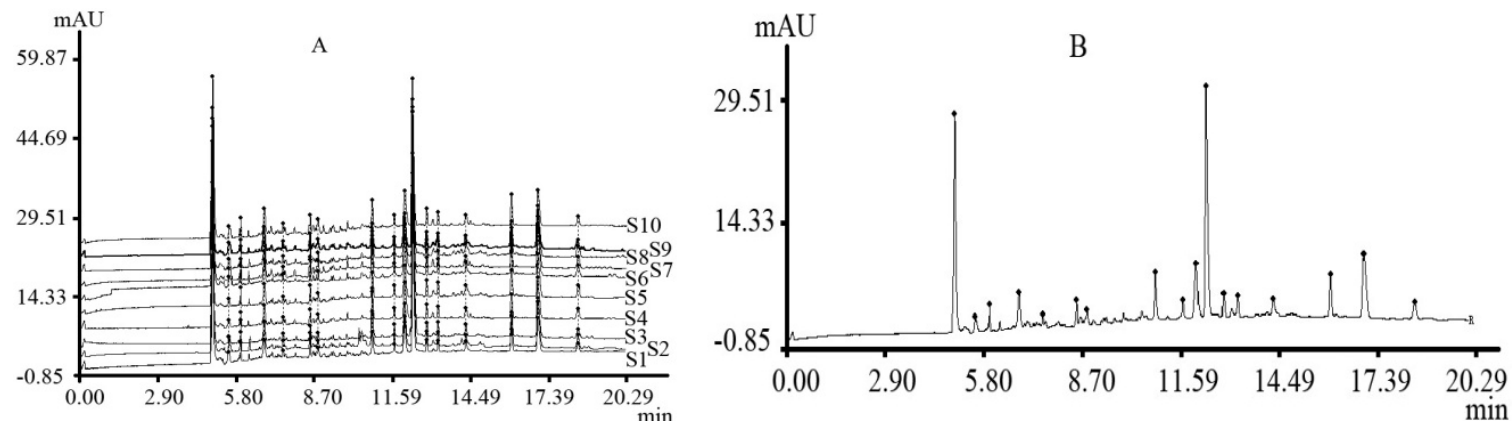

Figure 5: $\mathrm{A}=$ the overlay HPCE figerprints of 10 Rhizoma Chuanxiong water extract by SES software; $\mathrm{B}=$ the reference standard fingerprint of Rhizoma Chuanxiong water extract by SES software. Key: S1 = Mengyang town, Peng region; S2 = Aoping town, Peng region; S3 = Aoping town, Peng region; S4 = Xindu town, Xindu region; S5 = Xindu town, Xindu region; S6 = Shiyang town, Dujiangyan; S7 = Shiyang town, Dujiangyan; S8 = Zhuwa town, Dujiangyan; S9 = Daguan town, Dujiangyan; S10 = Daguan town, Dujiangyan 


\section{DISCUSSION}

Against HPLC, CZE presents four outstanding advantages: (a) the CZE separation is faster, (b) it has low requirement for sample pretreatment, (c) reagents consumption is low, and (d) capillaries are less expensive than HPLC columns. In this paper, the baseline separation of most of seventeen detectable peaks in Rhizoma Chuanxiong water extract was completed within $21 \mathrm{~min}$, and $5 \%$ acetonitrile alone was used as organic solvent modifier in the buffer.

The mean cost of a $75 \mathrm{~cm}$ capillary made in China was less than US $\$ 15.00$, which is much cheaper than HPLC column (usually more than $\$ 330$ ). Also, since HPCE capillary can tolerate high pressure rinsing procedures, CE capillary can be easily regenerated. Electroosmosis not only affects efficiency but also resolution, migration time and detector performance in HPCE analysis. The relative standard deviation for retention time and peak area of the main peaks demonstrate that a relative stable electroosmosis was obtained by optimizing the rinsing procedure.

\section{CONCLUSION}

Appropriate capillary rinsing is a simple method that is helpful for developing fingerprints of multicomponent samples without adding markers/internal standards. This method is simple, fast, reliable and environment-friendly using capillary zone electrophoresis with photodiode array detection for the fingerprint analysis of Rhizoma Chuanxiong water extract.

\section{ACKNOWLEDGEMENT}

This study was supported by the National Natural Science Foundation of the People's Republic of China (no. 30500668).

\section{REFERENCES}

1. Pharmcopoeia of the people's republic of China. China Medical Science and Technology Press: Beijing Vol I; 2010; pp 361-363.

2. Fritz JS. Recent developments in the separation of inorganic and small organic ions by capillary electrophoresis. J Chromatogr A 2000; 884: 261-75.

3. Faller $T$, Engelhardt $H$. How to achieve higher repeatability and reproducibility in capillary electrophoresis. $J$ Chromatogr A 1999; 853: 83-94.

4. Suntornsuk L, Anurukvorakun O. Precision improvement for the analysis of flavonoids in selected Thai plants by capillary zone electrophoresis. Electrophoresis 2005; 26 : 648-660.

5. Blanco-Heras GA, Turnes-Carou MI, Lopez-Mahia P, Muniategui-Lorenzo S, Prada-Rodriguez D, FernandezFernandez E. Capillary electrophoretic method for the determination of inorganic and organic anions in real samples. J Chromatogr A 2007; 1144: 275-278.

6. Gómez JE, Sandoval JE. The effect of conditioning of fused-silica capillaries on their electrophoretic performance. Electrophoresis 2008; 29: 381-392

7. Pharmcopoeia of the pepole's republic of China. China Medical Science and Technology Press: Beijing.Vol I; 2010. P 38.

8.Jin Y, Liang T, Fu Q, Xiao YS, Feng JT, Ke YX, Liang XM. Fingerprint analysis of Ligusticum chuanxiong using hydrophilic interaction chromatography and reversedphase liquid chromatography. J Chromatogr A 2009; 1216: 2136-2141.

9. Xie G, Zhao A, Li P, Li L, Jia W. Fingerprint analysis of Rhizoma chuanxiong by pressurized capillary electrochromatography and high-performance liquid chromatography. Biomed Chromatogr 2007; 21: 867875.

10. Chu QC, Zhan DL, Zhang HT, Ye JN. Study on Rhizoma Chuanxiong based on capillary electrophoresis with amperometric detection. Chinese Chemical Letters 2010; 21: $217-220$.

11. Sarmini K, Kendler E. Influence of organic solvent on separation selectivity in capillary electrophoresis, J. Chromatogr. A 1997; 792: 3-12.

12. Raber G, Greschonig $H$. New preconditioning strategy for the determination of inorganic anions with capillary zone electrophoresis using indirect UV detection. J Chromatogr A 2000; 890: 355-361.

13. Cohen N, Grushka E. Controlling electroosmotic flow in capillary zone electrophoresis. J Chromatogr A 1994; 678: 167-75.

14. Mayer BX. How to increase precision in capillary electrophoresis. J Chromatogr A 2001; 907: 21-37.

15. Yang LW, Wu DH, Tang $X$, Peng $W$, Wang $X R$, Ma $Y$, Su WW. Fingerprint quality control of Tianjihuang by highperformance liquid chromatography-photodiode array detection. J Chromatogr A 2005; 1070: 35-42. 